\title{
Bringing Continuing Medical Education to the Bedside: The University of California, San Francisco Hospitalist Mini-College
}

\author{
Niraj L. Sehgal, MD, MPH ${ }^{1 *}$, Robert M. Wachter, MD¹, Arpana R. Vidyarthi, MD²
}

${ }^{1}$ Division of Hospital Medicine, University of California, San Francisco, San Francisco, California; ${ }^{2}$ Singapore Health Services, Healthcare Leadership College, Duke-NUS Graduate Medical School, Singapore.

INTRODUCTION: As a relatively new generalist specialty, hospitalists must acquire new competencies that may not have been taught during their training years. Continuing medical education (CME) has traditionally been a mechanism to meet training needs but often fails to apply adult learning principles and fulfill current demands.

METHODS: We developed an innovative 3-day course called the University of California, San Francisco Hospitalist Mini-College (UHMC) that brings adult learners to the bedside for small-group learning focused on content areas relevant to today's hospitalists. The program was built on a structure of 4 clinical domains and 2 clinical skills labs. Sessions about patient safety and immersion into traditional academic learning vehicles, such as morning report and a morbidity and mortality conference, were also included. Participants completed a precourse survey and a postcourse evaluation.
RESULTS: Over 5 years, 152 participants enrolled and completed the program; $91 \%$ completed the pre-UHMC survey and $89 \%$ completed the postcourse evaluation. Overall, participants rated the quality of the UHMC course highly $(4.65 ; 1-5$ scale). Ninety-eight percent of UHMC participants $(n=57)$ in 2011 to 2012 reported a "high" or "definite" likelihood to change practice, higher than the $78 \%$ reported by the 11,447 participants in other UCSF CME courses during the same time period.

DISCUSSION: The UHMC successfully brought participants to an academic health center for a participatory, hands-on, and small-group learning experience that was highly rated. A shift of CME from a hotel conference room to the bedside is feasible, valued by participants, and offers a new paradigm for how to maintain and improve hospitalist competencies. Journal of Hospital Medicine 2014;9:129-134. (C) 2013 Society of Hospital Medicine.
"I hear and I forget, I see and I remember, I do and I understand."

Confucius

Hospital medicine, first described in $1996,{ }^{1}$ is the fastest growing specialty in United States medical history, now with approximately 40,000 practitioners. $^{2}$ Although hospitalists undoubtedly learned many of their key clinical skills during residency training, there is no hospitalistspecific residency training pathway and a limited number of largely research-oriented fellowships. ${ }^{3}$ Furthermore, hospitalists are often asked to care for surgical patients, those with acute neurologic disorders, and patients in intensive care units, while also contributing to quality improvement and patient safety initiatives. ${ }^{4}$ This suggests that the vast majority of hospitalists have not had specific training in many key competencies for the field. ${ }^{5}$

Continuing medical education (CME) has traditionally been the mechanism to maintain, develop, or increase the knowledge, skills, and professional per-

*Address for correspondence and reprint requests: Niraj L. Sehgal, MD, Associate Professor of Medicine, University of California, San Francisco, 533 Parnassus Avenue, Box 0131, San Francisco, CA 94143; Telephone: 415-476-0723; Fax: 415-476-4818; E-mail: nirajs@medicine.ucsf.edu

Additional Supporting Information may be found in the online version of this article.

Received: October 6, 2013; Accepted: October 17, 2013 2013 Society of Hospital Medicine DOI 10.1002/jhm.2111 Published online in Wiley Online Library (Wileyonlinelibrary.com). formance of physicians. ${ }^{6}$ Most CME activities, including those for hospitalists, are staged as live events in hotel conference rooms or as local events in a similarly passive learning environment (eg, grand rounds and medical staff meetings). Online programs, audiotapes, and expanding electronic media provide increasing and alternate methods for hospitalists to obtain their required CME. All of these activities passively deliver content to a group of diverse and experienced learners. They fail to take advantage of adult learning principles and may have little direct impact on professional practice. ${ }^{7,8}$ Traditional CME is often derided as a barrier to innovative educational methods for these reasons, as adults learn best through active participation, when the information is relevant and practically applied. ${ }^{9,10}$

To provide practicing hospitalists with necessary continuing education, we designed the University of California, San Francisco (UCSF) Hospitalist MiniCollege (UHMC). This 3-day course brings adult learners to the bedside for small-group and active learning focused on content areas relevant to today's hospitalists. We describe the development, content, outcomes, and lessons learned from UHMC's first 5 years.

\section{METHODS}

\section{Program Development}

We aimed to develop a program that focused on curricular topics that would be highly valued by practicing hospitalists delivered in an active learning small-group environment. We first conducted an 


\begin{tabular}{|c|c|c|}
\hline Day 1 & Day 2 & Day 3 \\
\hline $\begin{array}{c}\text { 8:45a - 9:45a } \\
\text { Welcome \& Course Introduction } \\
\text { 9:45a-12:00p: } \\
\text { Morning Report: } \\
\text { Case Presentation with } \\
\text { UCSF Master Clinician } \\
\text { Building Diagnostic Acumen: } \\
\text { A Session on Clinical Reasoning }\end{array}$ & $\begin{array}{c}\text { 8:45a-10:15a } \\
\text { Root Cause Analysis: } \\
\text { Thinking about Systems and Errors } \\
\frac{\text { BREAK \& SWITCH GROUPS }}{\frac{\text { Clinical Skills Lab I }}{10: 30 \mathrm{a}-12: 00 p}} \\
\text { Interpretation of Radiographic Studies }\end{array}$ & $\begin{array}{c}\text { 8:45a-11:45a } \\
\text { Clinical Skills Lab Il: } \\
\text { Use of Ultrasound and Enhancing } \\
\text { Confidence in Performing Bedside } \\
\text { Procedures } \\
\text { [Central Lines, Thoracentesis, and } \\
\text { Paracentesis] }\end{array}$ \\
\hline $\begin{array}{c}\text { 12:00p-1:00p } \\
\text { Lunch and Networking }\end{array}$ & $\begin{array}{l}\text { 12:00p-1:00p } \\
\text { Lunch and Meet the Professor }\end{array}$ & $\begin{array}{c}12: 00 \mathrm{p}-1: 00 \mathrm{p} \\
\text { UCSF Department of Medicine Case } \\
\text { Conference }\end{array}$ \\
\hline $\begin{array}{l}\text { 1:15-4:45p } \\
\text { *Clinical Domain I: } \\
\text { Hospital-based Neurology } \\
\text { on the Wards } \\
\text { Patient Care Rounds } \\
\text { Clinical Bedside Teaching } \\
\text { Small Group Didactics }\end{array}$ & $\begin{array}{c}\text { 1:15-4:45p } \\
{ }^{*} \text { Clinical Domain II: } \\
\text { Critical Care Medicine } \\
\text { in the ICU } \\
\text { Patient Care Rounds } \\
\text { Clinical Bedside Teaching } \\
\text { Small Group Didactics }\end{array}$ & $\begin{array}{c}\text { 1:15-4:45p } \\
\text { *Clinical Domain III: } \\
\text { Surgical Co-Management \& } \\
\text { Medical Consultation on the Wards } \\
\text { AND } \\
\text { *Clinical Domain IV: } \\
\text { Dermatology for the Hospitalist }\end{array}$ \\
\hline $\begin{array}{l}\text { 5:00p } \\
\text { Wrap-up }\end{array}$ & $\begin{array}{l}\text { 5:00p } \\
\text { Wrap-up }\end{array}$ & $\begin{array}{c}\text { 5:00p } \\
\text { Course Wrap-up } \\
\text { and UHMC Happy Hour }\end{array}$ \\
\hline
\end{tabular}

FIG. 1. University of California, San Francisco (UCSF) Hospitalist Mini-College sample schedule. ${ }^{*}$ Clinical domain sessions are repeated each afternoon as participants are divided into 3 smaller groups. Abbreviations: ICU, intensive care unit; UHMC, University of California, San Francisco Hospitalist Mini-College.

informal needs assessment of community-based hospitalists to better understand their roles and determine their perceptions of gaps in hospitalist training compared to current requirements for practice. We then reviewed available CME events targeting hospitalists and compared these curricula to the gaps discovered from the needs assessment. We also reviewed the Society of Hospital Medicine's core competencies to further identify gaps in scope of practice. ${ }^{4}$ Finally, we reviewed the literature to identify CME curricular innovations in the clinical setting and found no published reports.

\section{Program Setting, Participants, and Faculty}

The UHMC course was developed and offered first in 2008 as a "precourse" to the UCSF Management of the Hospitalized Medicine course, a traditional CME offering that occurs annually in a hotel setting. ${ }^{11}$ The UHMC takes place on the campus of UCSF Medical Center, a 600-bed academic medical center in San Francisco. Registered participants were required to complete limited credentialing paperwork, which allowed them to directly observe clinical care and interact with hospitalized patients. Participants were not involved in any clinical decision making for the patients they met or examined. The course was limited to a maximum of 33 participants annually to optimize active participation, small-group bedside activities, and a personalized learning experience. UCSF faculty selected to teach in the UHMC were chosen based on exemplary clinical and teaching skills. They collaborated with course directors in the development of their session-specific goals and curriculum.

\section{Program Description}

Figure 1 is a representative calendar view of the 3-day UHMC course. The curricular topics were selected based on the findings from our needs assessment, our ability to deliver that curriculum using our smallgroup active learning framework, and to minimize overlap with content of the larger course. Course curriculum was refined annually based on participant feedback and course director observations.

The program was built on a structure of 4 clinical domains and 2 clinical skills labs. The clinical domains included: (1) Hospital-Based Neurology, (2) Critical Care Medicine in the Intensive Care Unit, (3) Surgical Comanagement and Medical Consultation, and (4) Hospital-Based Dermatology. Participants were divided into 3 groups of $\sim 10$ participants each and rotated through each domain in the afternoons. The clinical skills labs included: (1) Interpretation of Radiographic Studies and (2) Use of Ultrasound and Enhancing Confidence in Performing Bedside Procedures. We also developed specific sessions to teach about patient safety and to allow course attendees to participate in traditional academic learning vehicles (eg, a Morning Report and Morbidity and Mortality case conference). Below, we describe each session's format and content.

\section{Clinical Domains \\ Hospital-Based Neurology}

Attendees participated in both bedside evaluation and case-based discussions of common neurologic conditions seen in the hospital. In small groups of $\sim 5$, 
participants were assigned patients to examine on the neurology ward. After their evaluations, they reported their findings to fellow participants and the faculty, setting the foundation for discussion of clinical management, review of neuroimaging, and exploration of current evidence to inform the patient's diagnosis and management. Participants and faculty then returned to the bedside to hone neurologic examination skills and complete the learning process. Given the unpredictability of what conditions would be represented on the ward in a given day, review of commonly seen conditions was always a focus, such as stroke, seizures, delirium, and neurologic examination pearls.

\section{Critical Care}

Attendees participated in case-based discussions of common clinical conditions with similar review of current evidence, relevant imaging, and bedside exam pearls for the intubated patient. For this domain, attendees also participated in an advanced simulation tutorial in ventilator management, which was then applied at the bedside of intubated patients. Specific topics covered include sepsis, decompensated chronic obstructive lung disease, vasopressor selection, novel therapies in critically ill patients, and use of clinical pathways and protocols for improved quality of care.

\section{Surgical Comanagement and Medical Consultation}

Attendees participated in case-based discussions applying current evidence to perioperative controversies and the care of the surgical patient. They also discussed the expanding role of the hospitalist in nonmedical patients.

\section{Hospital-Based Dermatology}

Attendees participated in bedside evaluation of acute skin eruptions based on available patients admitted to the hospital. They discussed the approach to skin eruptions, key diagnoses, and when dermatologists should be consulted for their expertise. Specific topics included drug reactions, the red leg, life-threating conditions (eg, Stevens-Johnson syndrome), and dermatologic examination pearls. This domain was added in 2010.

\section{Clinical Skills Labs}

\section{Radiology}

In groups of $\sim 15$, attendees reviewed common radiographs that hospitalists frequently order or evaluate (eg, chest x-rays; kidney, ureter, and bladder; placement of endotracheal or feeding tube). They also reviewed the most relevant and "not-to-miss" findings on other commonly ordered studies such as abdominal or brain computerized tomography scans.

\section{Hospital Procedures With Bedside Ultrasound}

Attendees participated in a half-day session to gain experience with the following procedures: paracente- sis, lumbar puncture, thoracentesis, and central lines. They participated in an initial overview of procedural safety followed by hands-on application sessions, in which they rotated through clinical workstations in groups of $\sim 5$. At each work station, they were provided an opportunity to practice techniques, including the safe use of ultrasound on both live (standardized patients) and simulation models.

\section{Other Sessions}

\section{Building Diagnostic Acumen and Clinical Reasoning}

The opening session of the UHMC reintroduces attendees to the traditional academic "morning report" format, in which a case is presented and participants are asked to assess the information, develop differential diagnoses, discuss management options, and consider their own clinical reasoning skills. This provides frameworks for diagnostic reasoning, highlights common cognitive errors, and teaches attendees how to develop expertise in their own diagnostic thinking. The session also sets the stage and expectation for active learning and participation in the UHMC.

\section{Root Cause Analysis and Systems Thinking}

As the only nonclinical session in the UHMC, this session introduces participants to systems thinking and patient safety. Attendees participate in a root cause analysis role play surrounding a serious medical error and discuss the implications, their reflections, and then propose solutions through interactive table discussions. The session also emphasizes the key role hospitalists should play in improving patient safety.

\section{Clinical Case Conference}

Attendees participated in the weekly UCSF Department of Medicine Morbidity and Mortality conference. This is a traditional case conference that brings together learners, expert discussants, and an interesting or challenging case. This allows attendees to synthesize much of the course learning through active participation in the case discussion. Rather than creating a new conference for the participants, we brought the participants to the existing conference as part of their UHMC immersion experience.

\section{Meet the Professor}

Attendees participated in an informal discussion with a national leader (R.M.W.) in hospital medicine. This allowed for an interactive exchange of ideas and an understanding of the field overall.

\section{Online Search Strategies}

This interactive computer lab session allowed participants to explore the ever-expanding number of online resources to answer clinical queries. This session was replaced in 2010 with the dermatology clinical domain based on participant feedback. 
TABLE 1. UHMC Participant Demographics

\begin{tabular}{|c|c|c|c|c|c|c|c|}
\hline Question & Response Options & $2008(n=4)$ & $2009(n=26)$ & $2010(n=29)$ & $2011(n=31)$ & $2012(n=28)$ & Average $(n=138)$ \\
\hline \multirow[t]{4}{*}{ How long have you been a hospitalist? } & $<2$ years & $52 \%$ & $35 \%$ & $37 \%$ & $30 \%$ & $25 \%$ & $36 \%$ \\
\hline & $2-4$ years & $26 \%$ & $39 \%$ & $30 \%$ & $30 \%$ & $38 \%$ & $32 \%$ \\
\hline & $5-10$ years & $11 \%$ & $17 \%$ & $15 \%$ & $26 \%$ & $29 \%$ & $20 \%$ \\
\hline & $>10$ years & $11 \%$ & $9 \%$ & $18 \%$ & $14 \%$ & $8 \%$ & $12 \%$ \\
\hline \multirow[t]{3}{*}{ How many hospitalist jobs have you had? } & 1 & $63 \%$ & $61 \%$ & $62 \%$ & $62 \%$ & $58 \%$ & $62 \%$ \\
\hline & 2 to 3 & $37 \%$ & $35 \%$ & $23 \%$ & $35 \%$ & $29 \%$ & $32 \%$ \\
\hline & $>3$ & $0 \%$ & $4 \%$ & $15 \%$ & $1 \%$ & $13 \%$ & $5 \%$ \\
\hline \multirow[t]{4}{*}{ How satisfied are you with your current position? } & Not satisfied & $1 \%$ & $4 \%$ & $4 \%$ & $4 \%$ & $0 \%$ & $4 \%$ \\
\hline & Somewhat satisfied & $11 \%$ & $13 \%$ & $39 \%$ & $17 \%$ & $17 \%$ & $19 \%$ \\
\hline & Pretty satisfied & $59 \%$ & $52 \%$ & $35 \%$ & $57 \%$ & $38 \%$ & $48 \%$ \\
\hline & Very satisfied & $26 \%$ & $30 \%$ & $23 \%$ & $22 \%$ & $46 \%$ & $29 \%$ \\
\hline \multirow[t]{4}{*}{ What do you love most about your job? } & Clinical care & $85 \%$ & $61 \%$ & $65 \%$ & $84 \%$ & $67 \%$ & $72 \%$ \\
\hline & Teaching & $1 \%$ & $17 \%$ & $12 \%$ & $1 \%$ & $4 \%$ & $7 \%$ \\
\hline & Ql or safety work & $0 \%$ & $4 \%$ & $0 \%$ & $1 \%$ & $8 \%$ & $3 \%$ \\
\hline & Other (not specified) & $14 \%$ & $18 \%$ & $23 \%$ & $14 \%$ & $21 \%$ & $18 \%$ \\
\hline \multirow[t]{5}{*}{ What percent of your time is spent doing clinical care? } & $100 \%$ & $39 \%$ & $36 \%$ & $52 \%$ & $46 \%$ & $58 \%$ & $46 \%$ \\
\hline & $75 \%-100 \%$ & $58 \%$ & $50 \%$ & $37 \%$ & $42 \%$ & $33 \%$ & $44 \%$ \\
\hline & $50-75 \%$ & $0 \%$ & $9 \%$ & $11 \%$ & $12 \%$ & $4 \%$ & $7 \%$ \\
\hline & $25 \%-50 \%$ & $4 \%$ & $5 \%$ & $0 \%$ & $0 \%$ & $5 \%$ & $3 \%$ \\
\hline & $<25 \%$ & $0 \%$ & $0 \%$ & $0 \%$ & $0 \%$ & $0 \%$ & $0 \%$ \\
\hline
\end{tabular}

NOTE: Abbreviations: QI, quality improvement; UHMC, University of California, San Francisco Hospitalist Mini-College.

TABLE 2. UHMC Participant Clinical Activities

\begin{tabular}{|c|c|c|c|c|c|c|c|}
\hline Question & Response Options & $2008(n=24)$ & $2009(n=26)$ & $2010(n=29)$ & $2011(n=31)$ & $2012(n=28)$ & Average $(n=138)$ \\
\hline $\begin{array}{l}\text { Do you primarily manage patients with } \\
\text { neurologic disorders in your hospital? }\end{array}$ & Yes & $62 \%$ & $50 \%$ & $62 \%$ & $62 \%$ & $63 \%$ & $60 \%$ \\
\hline Do you primarily manage critically ill & Yes and without an intensivist & $19 \%$ & $23 \%$ & $19 \%$ & $27 \%$ & $21 \%$ & $22 \%$ \\
\hline \multirow[t]{2}{*}{ ICU patients in your hospital? } & Yes but with an intensivist & $54 \%$ & $50 \%$ & $44 \%$ & $42 \%$ & $67 \%$ & $51 \%$ \\
\hline & № & $27 \%$ & $27 \%$ & $37 \%$ & $31 \%$ & $13 \%$ & $27 \%$ \\
\hline $\begin{array}{l}\text { Do you perform preoperative medical } \\
\text { evaluations and medical consultation? }\end{array}$ & Yes & $96 \%$ & $91 \%$ & $96 \%$ & $96 \%$ & $92 \%$ & $94 \%$ \\
\hline \multirow{3}{*}{$\begin{array}{l}\text { Which of the following describes your } \\
\text { role in the care of surgical patients? }\end{array}$} & Traditional medical consultant & $33 \%$ & $28 \%$ & $28 \%$ & $30 \%$ & $24 \%$ & $29 \%$ \\
\hline & Comanagement (shared responsibility with surgeon) & $33 \%$ & $34 \%$ & $42 \%$ & $39 \%$ & $35 \%$ & $37 \%$ \\
\hline & Attending of record with surgeon acting as consultant & $26 \%$ & $24 \%$ & $26 \%$ & $30 \%$ & $35 \%$ & $28 \%$ \\
\hline $\begin{array}{l}\text { Do you have bedside ultrasound available } \\
\text { in your daily practice? }\end{array}$ & Yes & $38 \%$ & $32 \%$ & $52 \%$ & $34 \%$ & $38 \%$ & $39 \%$ \\
\hline
\end{tabular}

NOTE: Abbreviations: ICU, intensive care unit; UHMC, University of California, San Francisco Hospitalist Mini-College.

\section{Program Evaluation}

Participants completed a pre-UHMC survey that provided demographic information and attributes about themselves, their clinical practice, and experience. Participants also completed course evaluations consistent with Accreditation Council for Continuing Medical Education standards following the program. The questions asked for each activity were rated on a 1-to-5 scale $(1=$ poor, $5=$ excellent $)$ and also included openended questions to assess overall experiences.

\section{RESULTS}

\section{Participant Demographics}

During the first 5 years of the UHMC, 152 participants enrolled and completed the program; 91\% completed the pre-UHMC survey and $89 \%$ completed the postcourse evaluation. Table 1 describes the selfreported participant demographics, including years in practice, number of hospitalist jobs, overall job satis- faction, and time spent doing clinical work. Overall, $68 \%$ of all participants had been self-described hospitalists for $<4$ years, with $62 \%$ holding only 1 hospitalist job during that time; $77 \%$ reported being "pretty" or "very satisfied" with their jobs, and $72 \%$ reported clinical care as the attribute they love most in their job. Table 2 highlights the type of work attendees participate in within their clinical practice. More than half manage patients with neurologic disorders and care for critically ill patients, whereas virtually all perform preoperative medical evaluations and medical consultation

\section{Participant Experience}

Overall, participants rated the quality of the UHMC course highly $(4.65 ; 1-5$ scale). The neurology clinical domain (4.83) and clinical reasoning session (4.72) were the highest-rated sessions. Compared to all UCSF CME course offerings between January 2010 
TABLE 3. Selected UHMC Participant Comments From Program Evaluations

"Great pearls, broad ranging discussion of many controversial and common topics, and I loved the
teaching format."
"I thought the conception of the teaching model was really effective—-hands-on exams in small
groups, each demonstrating a different part of the neurologic exam, followed by presentation
and discussion, and ending in bedside rounds with the teaching faculty."
"Excellent review of key topics—-wide variety of useful and practical points. Very high application
value."
"Great course. I'd take it again and again. It was a superb opportunity to review technique, equip-
ment, and clinical decision making."
"Overall outstanding course! Very informative and fun. Format was great."
"Forward and clinically relevant. Like the bedside teaching and how they did it.The small size of the
course and the close attention paid by the faculty teaching the course combined with the oppor-
tunity to see and examine patients in the hospital was outstanding."

NOTE: Abbreviations: UHMC, University of California, San Francisco Hospitalist Mini-College.

and September 2012, the UHMC rated higher than the cumulative overall rating from those 227 courses $(4.65$ vs 4.44). For UCSF CME courses offered in 2011 and 2012, $78 \%$ of participants $(\mathrm{n}=11,447)$ reported a "high" or "definite" likelihood to change practice. For UHMC participants during the same time period $(\mathrm{n}=57), 98 \%$ reported a similar likelihood to change practice. Table 3 provides selected participant comments from their postcourse evaluations.

\section{DISCUSSION}

We developed an innovative CME program that brought participants to an academic health center for a participatory, hands-on, and small-group experience. They learned about topics relevant to today's hospitalists, rated the experience very highly, and reported a nearly unanimous likelihood to change their practice. Reflecting on our program's first 5 years, there were several lessons learned that may guide others committed to providing a similar CME experience.

First, hospital medicine is a dynamic field. Conducting a needs assessment to match clinical topics to what attendees required in their own practice was critical. Iterative changes from year to year reflected formal participant feedback as well as informal conversations with the teaching faculty. For instance, attendees were not only interested in the clinical topics but often wanted to see examples of clinical pathways, order sets, and other "systems" in place to improve care for patients with common conditions. Our participant presurvey also helped identify and reinforce the curricular topics that teaching faculty focused on each year. Being responsive to the changing needs of hospitalists and the environment is a crucial part of providing a relevant CME experience.

We also used an innovative approach to teaching, founded in adult and effective CME learning principles. CME activities are geared toward adult physicians, and studies of their effectiveness recommend that sessions should be interactive and utilize multiple modalities of learning. ${ }^{12}$ When attendees actively participate and are provided an opportunity to practice skills, it may have a positive effect on patient outcomes. ${ }^{13}$ All UHMC faculty were required to couple presentations of the latest evidence for clinical topics with small-group and hands-on learning modalities. This also required that we utilize a teaching faculty known for both their clinical expertise and teaching recognition. Together, the learning modalities and the teaching faculty likely accounted for the highly rated course experience and likelihood to change practice.

Finally, our course brought participants to an academic medical center and into the "mix of clinical care" as opposed to the more traditional hotel venue. This was necessary to deliver the curriculum as described, but also had the unexpected benefit of energizing the participants. Many had not been in a teaching setting since their residency training, and bringing them back into this milieu motivated them to learn and share their inspiration. As there are no published studies of CME experiences in the clinical environment, this observation is noteworthy and deserves to be explored and evaluated further.

What are the limitations of our approach to bringing CME to the bedside? First, the economics of an intensive 3-day course with a maximum of 33 attendees are far different than those of a large hotel-based offering. There are no exhibitors or outside contributions. The cost of the course to participants is $\$ 2500$ (discounted if attending the larger course as well), which is 2 to 3 times higher than most traditional CME courses of the same length. Although the cost is high, the course has sold out each year with a waiting list. Part of the cost is also faculty time. The time, preparation, and need to "teach on the fly" to meet the differing participant educational needs is fundamentally different than delivering a single lecture in a hotel conference room. Not surprisingly, our faculty enjoy this teaching opportunity and find it equally unique and valuable; no faculty have dropped out of teaching the course, and many describe it as 1 of the teaching highlights of the year. Scalability of the UHMC is challenging for these reasons, but our model could be replicated in other teaching institutions, even as a local offering for their own providers.

In summary, we developed a hospital-based, highly interactive, small-group CME course that emphasizes case-based teaching. The course has sold out each year, and evaluations suggest that it is highly valued and is meeting curricular goals better than more traditional CME courses. We hope our course description and success may motivate others to consider moving beyond the traditional CME for hospitalists and explore further innovations. With the field growing and changing at a rapid pace, innovative CME experiences will be necessary to assure that hospitalists continue to provide exemplary and safe care to their patients. 


\section{Acknowledgements}

The authors thank Kapo Tam for her program management of the UHMC, and Katherine $\mathrm{Li}$ and Zachary Martin for their invaluable administrative support and coordination. The authors are also indebted to faculty colleagues for their time and roles in teaching within the program. They include Gupreet Dhaliwal, Andy Josephson, Vanja Douglas, Michelle Milic, Brian Daniels, Quinny Cheng, Lindy Fox, Diane Sliwka, Ralph Wang, and Thomas Urbania.

Disclosure: Nothing to report.

\section{References}

1. Wachter RM, Goldman L. The emerging role of "hospitalists" in the American health care system. N Engl J Med. 1996;337(7):514-517.

2. Society of Hospital Medicine. Available at: http://www.hospitalmedi cine.org/Content/NavigationMenu/Membership2/HospitalFocused Practice/Hospital_Focused_Pra.htm. Accessed October 1, 2013.

3. Ranji SR, Rosenman DJ, Amin AN, Kripalani S. Hospital medicine fellowships: works in progress. Am J Med. 2006;119(1): 72.e1-e7.

4. Society of Hospital Medicine. Core competencies in hospital medicine. Available at: http://www.hospitalmedicine.org/Content/NavigationMenu/Education/CoreCurriculum/Core_Competencies.htm. Accessed October 1, 2013.

5. Sehgal NL, Wachter RM. The expanding role of hospitalists in the United States. Swiss Med Wkly. 2006;136(37-38);591-596.
6. Accreditation Council for Continuing Medical Education. CME content: definition and examples Available at: http://www.accme.org/ requirements/accreditation-requirements-cme-providers/policies-anddefinitions/cme-content-definition-and-examples. Accessed October $1,2013$.

7. Davis DA, Thompson MA, Oxman AD, Haynes RB. Changing physician performance. A systematic review of the effect of continuing medical education strategies. JAMA. 1995;274(9):700-705.

8. Mazmanian PE, Davis DA. Continuing medical education and the physician as a learner: guide to the evidence. JAMA. 2002;288(9): 1057-1060.

9. Bower EA, Girard DE, Wessel K, Becker TM, Choi D. Barriers to innovation in continuing medical eduation. J Contin Educ Health Prof. 2008;28(3):148-156.

10. Merriam S. Adult learning theory for the 21st century. In: Merriam S. Thrid Update on Adult Learning Theory: New Directions for Adult and Continuing Education. San Francisco, CA: Jossey-Bass; 2008:93and 98.

11. .UCSF management of the hospitalized patient CME course. Available at: http://www.ucsfcme.com/2014/MDM14P01/info.html. Accessed October 1, 2013.

12. Continuing medical education effect on practice performance: effectiveness of continuing medical education: American College or Chest Physicians evidence-based educational guidelines. Chest. 2009;135(3 suppl);42S-48S.

13. Continuing medical education effect on clinical outcomes: effectiveness of continuing medical education: American College or Chest Physicians evidence-based educational guidelines. Chest. 2009;135(3 suppl);49S-55S. 